\title{
Analysis on the Comparison between English and Chinese Euphemisms
}

\author{
Wei Liu \\ School of Foreign Languages, Jilin Agricultural University, Changchun 130118, China. \\ 29897259@qq.com
}

Keywords: Euphemism; comparison; rhetoric.

\begin{abstract}
Euphemism is a proper means of expression people use in communication and exchange which is hoped to make communication smooth and pleasant. Euphemism is both a common language phenomenon and a social cultural phenomenon, which has penetrated in people's daily life, reflecting the widespread social phenomena or the psychology of the people, and at the same time is one of rhetorical devices commonly used in languages. There are many similarities and differences between English and Chinese euphemisms showing their national characteristics and cultural connotation. The comparative study of similarities and differences of origin, classifications and development trend between English and Chinese euphemisms is done in this paper to reveal their inner links.
\end{abstract}

\section{Introduction}

Euphemism refers to implicit or mildly expressions used to replace them which will make people unhappy or irreverent. Euphemism is a common phenomenon in human language, and in different language communities and social strata, there will be some specific methods to achieve the effect of expression of euphemism. Euphemisms exist at the very beginning of both Chinese and English. Euphemisms in English come from the Greek. "EU" means good or well and "pheme" means saying or speech and thus euphemism means comfortable or cosmetic words. And according to some Chinese scholars euphemism is tactful speech not talked about straightforwardly. But because of differences in history and culture between Chinese and English people, there are both similarities and differences of origin, classifications and development trend between English and Chinese euphemisms.

\section{The Origin of Euphemism}

The original euphemisms stem from religious superstition and social hierarchy generated by the hierarchy system, the fear of supernatural power and the appellations of bigwigs are probably the earliest human euphemisms. Because the ancient Greeks wanted to avoid calling Nemesis in the rituals, and called them the Eumenides (meaning friendly goddess) or Erinyes (the respectable). Many peoples believe that Azrael exists, so the ancients gave him a lot of fame in his appellation, such as The Great Leveller, The Great Whipper and the like. Since social hierarchies appeared in the history of human beings, the ruled tried to use linguistic strategies to refer to the ruler's worth and please rulers so as to protect themselves from injury resulting in a lot of appellations of euphemism. As in English, Majesty means supreme authority to respect the King or Queen, so in the presence of the King or Queen, they use Your Majesty, and when the King or Queen is absent, they use His/Her Majesty with indirect address. Excellency and Honorable are also known: Excellency refers to the governor, bishop, honorific and Honorable is before noble children and other senior officials before the name of the crown in Britain. In addition, anti discrimination struggle has created some appellation of euphemism, and the most typical example is a black Euphemism, which has changed from slaves, Negroes, the black people, the colored people to African Americans in the USA. Chinese appellation euphemism is more complex including appellation honorific title, and modest words or derogatory term. The emperors are called the Son of Heaven, and they also cheat people by calling themselves "ai jia" or "gua ren" and so on. Euphemism is a part of language, a reflection of culture, which has strong characteristics of the 
times. With the change of the times, the reform of the society, and people's democratic consciousness improved, many euphemisms gradually fade, and die.

\section{The Fields Related to Euphemisms}

Euphemisms can be divided into traditional euphemisms and stylistic euphemisms. The traditional euphemism is closely related to taboo things such as birth, death, disease, and so on. If the direct expression is taboo, people may feel vulgar, blunt, rude; conversely if an indirect expression, an euphemism, is used, the impression conveyed would be elegant, subtle, polite. Stylistic euphemism is actually compliment, praise and has nothing to do with taboo. In daily communication, in order to avoid stimulation, or to seek cooperation, sometimes hyperbole is used to express the practices of some unpleasant things. However, both of these two kinds of euphemisms are related to the fields as follows:

\subsection{Euphemisms about Some Physiological Defects, Body Functions and other Aspects.}

The euphemisms concerning body's physiological defects, or some of the human body functions, behaviors and other aspects are commonly used in the daily communication. For instance, in English, if a person is too fat, works like big, heavy, stout, plump, weight are often used instead of being too fat. If a person is not good-looking, people are not expected to use the word "ugly" to describe he or she but use “plain, ordinary or homely”. In Chinese, people use“腿脚不方便” and “行动不便” to refer to “the cripple” or “the blind ”, while in English “imperfect hearing” and "visually retarded" are used instead of "the deaf " and "the blind " and " queer " is used to express "homosexual” . People go to the toilet, which in English, is tactfully expressed as "to wash one's hand, to powder one's nose, to spend a penny, to pay a call, to go somewhere, to answer the call of nature”, while in Chinese “方便一下、去洗手间、去补一下妆” and the rest.

\subsection{Euphemisms about the Age.}

In the western world, the interests of the individuals are inviolable. Under the belief of a man's home is his castle, all with private life, such as age, weight, marriage, rich and poor, is expressed in a mild, indirect way. Influenced by this concept, talking about the "old" has become a very sensitive topic, especially in the presence of a lady is taboo. Therefore, people always try to avoid the word "old" in the communication. On the other hand, the Westerners put much emphasis on competition, and pay attention to efficiency, so being old means the decline of both effort and ability, and weaker than the young people and thus the elderly often suffer. In the consciousness of the elderly, "old" is synonymous with "useless", and it often makes people think of life of loneliness and desolation, so usually words like "old", "aged" and other words are replaced by some sweet words instead, such as "seasoned man", “elder statesman", "senior citizens", "the mature, the longer living”, "golden years", nursing homes has become "a home for adults or an adult community". The "old" has become the social psychological burden in the western world, but it is just opposite to China. Because in traditional Chinese culture and concepts, people pay much attention to the ancestor worship, advocating human ethics and the old people are widely respected in the society, and thus "old" is not terrible and euphemisms in this aspect are rare. And the question like how old are you? Is not the taboo.

\subsection{Euphemisms about Death.}

Because of different cultural background, there is a big difference in the perceptions about the death. In English speaking countries, Christianity plays an important role in people's life, and euphemisms about the death mostly come from the Bible, and are closely related to the Christian faith. Many Christians believe the "afterlife" and "original sin" in their opinion, and the death means "to go to heaven", "to be called to God" or "to cancel ones account". Christians think in the final trial, everyone would hand up their own books recording the doings in the world to God. In China, no religion has such important status and influence like Christianity in the English speaking countries. Euphemisms about the death in China reflect the variety of ideologies, religions and perceptions of life and death. And therefore, death euphemisms are more than them in English, for 
instance, the monk's death as “Nirvana”; the elderly die for “寿终正寝”; dying for “national interests” called “殉国”; dying together with the monarch “殉葬”; dying for defending the motherland as the "martyrs". It is perhaps incomprehensible for the Westerners due to the different cultural background. But there are still some similarities between two languages, for example, euphemisms about the death as "rest", "sleep", "final sleep", "to return to dust" and the rest, reflecting similarities of views about the death.

\subsection{Euphemisms about Occupations.}

Occupation euphemism refers to appellations that humble occupation and its practitioners were addressed. In the societies of the English speaking countries, there are white-collar workers and blue-collar workers and there is a big value gap between them, the connotation of which in fact is a sign of occupation discrimination. Therefore, many in the ordinary work of blue collar workers have been labeled the name of "engineer" in order to balance their mentality, reduce the psychological stimulation. Engineer has become the most active occupation euphemism. According to statistics, as many as two thousand kinds of occupations are beautified by the name of engineer. For instance, footwear maintenance engineer is in fact bootblack and recreation engineer refers to sanitary man. In addition, some occupation euphemisms are formed by the suffix - cian, - ist, - or added to the name of a total occupation. The principle is to use the name of technical personnel and administrative personnel to replace the ordinary staff, for example, calling the gardener as the landscape architect, the file clerk as research consultant, the dry cleaner as dry cleaning engineer, the barber as called a beautician and so on. In Chinese, occupation euphemisms are less them in English. The main reason is that due to the traditional vocational values make people have a strong dedication and, inter industry wages are also unlike the Anglo American countries as disparity. Therefore, people in society feel less professional inferiority to others, reducing demands of the occupation euphemisms. In recent years, with China's reform and opening up and the introduction of foreign capital and technology, foreign culture, ideology and values are also introduced. For example, canteen workers tend to say they work in diet, or general office work which indicates the development and expansion of Chinese Occupation euphemisms.

\section{The Development Trend of English and Chinese Euphemisms}

Euphemisms like many other language phenomena in English and Chinese are determined by laws of the development of languages and at the same time, it must be affected by their difference between two cultures and display different trends.

\subsection{The Common Trend of Development of English and Chinese Euphemisms.}

As a part of language, euphemism is also changing, with the features of the new superseding the old, and very fast. According to some linguists euphemism is governed by two laws to a great extent, one is Gresham's Law, the other is the Law of succession. Gresham 's Law is the concept of economics and its application in linguistics mainly refers to the fact that if a word has "positive "or" neutral" meaning, and "negative" one at the same time, then this "negative" one will eventually squeeze out its "positive "or" neutral" meaning. For instance, the word "gay" in English originally meant happy and joy, but gradually it has something to do with the homosexuality, so people began to avoid using the word "gay" and it has now been specifically used to refer to homosexual things.

The Law of successions is that a word is use as a euphemism but after a period of time, it loses the function of euphemisms, and then people will desert it and create a new euphemism. In Chinese the “toilet” euphemism reflected the law. Initially people with “茅房”as a euphemism. Later people felt it is not euphemistic enough so that some people use“一号” as a euphemism for toilet, and now people tend to use "hand washing".

\subsection{The Different Manifestations of Development in English and Chinese euphemisms.}


Although the development and change of language is determined by some laws, they are not uniform. The social development and cultural features must reflected in them. Therefore, the development of English and Chinese euphemisms surely display different characteristics.

Generally speaking, the change of Chinese euphemisms is not as obvious and rapid as English euphemisms. For instance, the word “occupy” had been used as a euphemism for sex, but now if not reminded, few people would think of occupy. This is the result of The Law of successions. But in Chinese it is not obvious. Such as “方便” as a euphemism for "toilet", first appeared in the classic novel "Journey to the West" and until now, people still often use as a euphemism for toilet. After hundreds of years of evolution, it is not abandoned by society, which in other languages is very rare.

\section{Conclusion}

Euphemism is both a common language phenomenon and a social cultural phenomenon, which has penetrated in people's daily life, reflecting the widespread social phenomena or the psychology of the people, and at the same time is one of rhetorical devices commonly used in languages reflecting the social and national characteristics. With many differences in social life, national character and traditional culture in China and English speaking countries, English and Chinese euphemisms show their splendor features. The analysis of the comparison between English and Chinese euphemisms can help language learners better grasp features of Chinese and English and promote further exchanges.

\section{References}

[1] Lina Xu Pragmatic and Discourse Strategies of the Translation of Euphemisms [J]. Chinese Translators Journal. Vol 24 (2008) No. 6, p15-19.

[2] Wenfen Tan. A Comparative Study on English and Chinese Euphemisms [J]. Journal of Chongqing Three Gorges University. (2005) No. 3, p93-95.

[3] Hui Yu. The Cultural Connotation Contrast of Chinese and English euphemism [J]. Journal of Dong jiang. (2002) No. 19, p76-79.

[4] Yanyan Chen. The Comparison of English and Chinese Cultures from the Perspective of Euphemisms [J].An Hui Literature. (2007) No. 12, p162-163.

[5] Guiyuan Li. Study on Euphemisms and Taboo in Chinese and English [J]. Journal of Tianjin Foreign University. (2004) No. 3, p48-50. 